\title{
Construction and Analysis of Lifelong Inclusive Education Model Based on Education 2030 Framework for Action
}

\author{
Feng Xia, Lian Lu*, Can Liu \\ Changning Special Education Guidance Center, Shanghai, China \\ Email address: \\ 13701910328@163.com (Feng Xia),2744053908@qq.com (Lian Lu), liucan09@163.com (Can Liu) \\ ${ }^{*}$ Corresponding author
}

To cite this article:

Feng Xia, Lian Lu, Can Liu. Construction and Analysis of Lifelong inclusive education Model Based on Education 2030 Framework for Action. International Journal of Elementary Education. Vol. 9, No. 2, 2020, pp. 37-45. doi: 10.11648/j.ijeedu.20200902.13

Received: June 5, 2020; Accepted: June 29, 2020; Published: July 13, 2020

\begin{abstract}
Inclusive education is a general trend in the development of world education and the inevitable requirement of education modernization in China. Lifelong Inclusive Education will become the direction of inclusive education in the future. This paper discusses the necessity and feasibility of lifelong inclusive education from both theoretical and empirical perspectives. Based on the Education 2030 Framework for Action, the paper put forward the theory model of lifelong inclusive education, discussed the constituent elements and the relationships among elements of lifelong education theoretical model. The theoretical model of lifelong inclusive education is a spatial structure, which includes three levels, consisting of three elements: the scope of inclusive education objects, the stage of inclusive education and the situation of lifelong inclusive education. At the same time, Changning district of Shanghai has formed some typical cases in the aspects of 0-3 years old special education support, community inclusive service for adults with disabilities, leisure and health care support service for disabled elderly, support service for gifted student, students learning in regular classrooms, thus demonstrating the feasibility of implementing lifelong inclusive education. Finally, the development of China's inclusive education is prospected. Inclusive education in China will step towards lifelong inclusive education and may take the lead in turning lifelong inclusive education into reality.
\end{abstract}

Keywords: Inclusive Education, Lifelong Inclusive Education, Education 2030 Framework for Action, Theoretical Model

\section{Introduction}

Inclusive education is the general trend of education and special education in the world. In 1994, the Salamanca Statement called on all countries to adopt inclusive education as a strategy to achieve education for all, and also emphasizing to change the whole education system to meet the needs of students in special education. From the perspective of international education trend, the United Nations Development Summit puts forward the overall education goal of "Ensure inclusive and equitable quality education and promote lifelong learning opportunities for all" in 2030 Agenda for Sustainable Development. In order to implement the above goals, UNESCO adopted the education 2030 program of action at the 38 th plenary session on November 4 , 2015, which proposed "to ensure inclusive and fair quality education and promote the chance of all people to lifelong learning" [1], including three elements of "inclusive", "all (citizens)" and "lifelong". This points out the direction for the development of inclusive education.

From the perspective of domestic policies, Tianshun Lee, the national inspector of education, pointed out that inclusive education is an important concept and proposition of special education. The report of the 16th National Congress of the Communist Party of China pointed out that "building a lifelong education system", the report of the 18th National Congress of the Communist Party of China proposed that "improving the lifelong education system" and "comprehensively promoting inclusive education" are the core tasks of special education in China's Education Modernization 2035. The Outline of Shanghai Mid-longTerm Education Reform and Development Plan (2010-2020) puts forward the core idea of "for the lifelong development of every student".

It can be seen that, no matter from the international education trend or the domestic policy background, the development of inclusive education is bound to be lifelong, and lifelong inclusive education will become the direction of 
the future development of inclusive education. Based on this, the study constructs a life-long inclusive education model from the scope of the inclusive education objects, stages and, situations. And the study makes an empirical analysis through literature data and practical cases, in order to provide a reference for the theoretical and practical research of inclusive education in China and a Chinese sample for the world inclusive education.

\section{Inclusive Education and Lifelong Inclusive Education}

Some domestic scholars [2] have proposed that the broad sense of inclusive education means that all disabled people can fully integrate into the general education system, including receiving higher education, vocational education, adult education and even realizing lifelong learning.

The lifelong inclusive education mentioned in this topic refers to the public education service of "Ensure inclusive and equitable quality education and promote lifelong learning opportunities for all".

The home of inclusive education is in ordinary schools, while. The main difference between lifelong inclusive education and inclusive education is that the home of lifelong inclusive education includes ordinary schools, communities and the whole society, which is not limited by places. Based on the theories of lifelong education and inclusive education, this study attempts to build a lifelong inclusive education system for those who need special education, and to provide lifelong career support services for the inclusive education objects under the guidance of community integration.

\section{Model Construction of Lifelong Inclusive Education}

In the process of constructing the model of lifelong inclusive education, we think systematically from three aspects: theoretical basis, constituent elements and hierarchical structure.

\subsection{Theoretical Basis}

Based on the theory of special education and inclusive education, lifelong learning and career development, ecological theory and situational education, three spatial structural elements of lifelong inclusive education are analyzed.

\subsubsection{Theory of Special and Inclusive Education}

According to the point of view of scholars in the field of special education, the scope of special education objects is defined differently. According to the dictionary of Education Edited by Mingyuan Gu (1990), special education generally refers to the education of abnormal children by special methods, means and facilities; while in the introduction to special education edited by Yongxin Park (1991), it divided children into extraordinary children's education, deaf children's education, blind children's education, backward children's education, speech disorder children's education, education for children with emotional and behavioral disorders, education for children with multiple disabilities, according to the types of special children [3]. From the perspective of national policy, no matter the second (2006) sample survey of disabled people or the sixth (2010) national census, the two results divide disabled people into seven categories: visual disability, hearing disability, speech disability, physical disability, intellectual disability, mental disability and multiple disabilities [4]. Therefore, the scope of special education objects in China has not been unified.

With the reform and development of international special education, "special students" has been redefined as "students with special education needs" by the academic community, including visual, hearing, intellectual, limb, cerebral palsy, autism spectrum disorders, multiple disorders, learning disabilities (attention deficit hyperactivity disorder, reading disorder, writing disorder, mathematics learning difficulties, etc.), emotional behavior disorders, speech language disorders, gift and sick students, etc. According to the data released by the U.S. Department of Education, in 2008, there were 13 types of special children receiving special education services in the United States, with different degrees, accounting for $11.74 \%$ of the total number of primary and secondary school students, while the main objects of special education services in China are the students with visual, listening and intellectual disabilities, accounting for $0.017 \%$ [5]. Therefore, in the field of special education, the scope of service objects of special education in China is far less than that in the field of international special education.

Since the 1970s, inclusive education "has become the main trend of global special education development"[6], students with special education needs to study in ordinary schools to receive inclusive education. In China, since 1987, the experiment of mainstreaming has gradually become the main form of special education in China, and has also become a practical inclusive education mode [7][8]. The objects of inclusive education in China mainly include three categories: vision disability, hearing disability and intellectual disability [9]. Although the more developed areas have expanded to 6-9 categories, more than $80 \%$ of the mainstreaming are the above three categories of students, and a large number of learning disabilities, language barriers other than visual, listening and intellectual disabilities and some students with special education needs are not included in the scope of inclusive education service.

It can be seen that there are great differences in the scope of inclusive education objects at home and abroad. The scope of inclusive education objects in mainland China is far smaller than that in developed countries such as the United States. In the field of international education, if we want to master the right of international discourse, we must make a breakthrough in the scope of inclusive education objects, break through the traditional three types of objects, and expand to all students with special education objects. 


\subsubsection{Theory of Lifelong Learning and Career Development}

Lifelong Learning is rooted in adult education, and gradually evolved into "lifelong education", and finally formed the concept of lifelong learning. Since the concept of lifelong education was put forward by Mr. Paul langrand in 1965, the international community has made a continuous and in-depth elaboration on it. In 1972, the United Nations Educational, scientific and Cultural Organization published fur Edgar's report "learning to survive", in which three basic concepts of "life-long education", "life-long learning" and "learning society" were put forward. Human existence is "an endless process of perfection and learning" (Li Yixian, 2004)[10]. Candy has made clear a concept of lifelong learning, which refers to a kind of learning after the end of formal school education with the primary purpose of acquiring the ability and skills that can make oneself continue to complete "self-education" (Candy P. C., 1991)[11]. On May 21, 2015, the world education forum hosted by UNESCO took "changing life through education" as the theme and adopted the Incheon declaration, which set a new global education goal for the next 15 years. All people should have the opportunity to receive inclusive and equal quality education and enjoy lifelong learning opportunities. Therefore, all people, including the disabled, should have the opportunity of lifelong learning.

According to the theory of career development [12], "career" integrates the role of a person's whole life, whose representative character is schuber. He puts forward the theory of five stages of career. He thinks that career is the evolution direction and course of various events in life. His career rainbow chart vividly shows the time-space relationship of career development, including the life span across a life, as well as the life space from top to bottom.

Thus, in the process of promoting inclusive education, we should pay attention to the lifelong learning needs and career development of individuals, and provide inclusive education services and support for each stage of their career development. inclusive education should be oriented to the whole life of individuals, and inclusive education will eventually move towards lifelong inclusive education.

\subsubsection{Theory of Ecological and Situated Education}

The ecological theory emphasizes that things are the internal unity, which can' t be interrupted. After Waller, e. and others introduced ecological theory into the field of education, Cremin, L. A., an American scholar, formally put forward the concept of "educational ecology", and the publication of school ecology by Eggleston, J., a British scholar, marked the formation of the theoretical system of educational students. The theory of educational ecology advocates using the principle of ecology to analyze the mutual influence and restriction mechanism of educational ecological environment, educational individual ecology, educational group ecology and educational ecological system with the thinking of overall linkage and system balance, so as to solve the educational problems. Educational ecosystem is the highest and most complex level of educational ecology, including both the system of education itself and the environmental system [13].
According to the theory, "the elements in the education system not only form a certain structure in the internal connection and interaction, but also exchange energy, material and information inside and outside the education system, with multi-dimensional inlay"[14]. According to this theory, for the construction of the model of lifelong inclusive education, we need to comprehensively consider the internal and external elements of the inclusive education system, which provides an important reference for the construction of the theoretical model of lifelong inclusive education.

The Theory of Situational Education is a native educational theory in China. It was put forward by Jilin Lee, a super teacher of Nantong Normal University in Jiangsu Province of China. The three dimensions of children knowledge society are the core of the theory. Situational Education emphasizes that students' active learning and development can be realized by creating situations, optimizing their living environment, combining cognition with emotion [15], which is the main connotation of situational education theory. According to Theory of Situational Education, we should provide an open system for children, devote ourselves to expanding children's life and development space, and extend it to family and society. Society is the widest classroom for children's learning activities, an indispensable resource for children's learning, "an irreplaceable real situation for children's knowledge construction" [16].

It can be seen that for lifelong inclusive education, our perspective should be placed in a broader space, so that the inclusive education can break through the space restrictions, from the school situation to the community situation, and even the whole society, to build an unlimited integrated ecology for children with special education needs.

\subsection{Components}

The lifelong inclusive education model is a spatial structure, which is analyzed from three aspects: the coverage of the inclusive education object, the span of the inclusive education stage and the ecology of the inclusive education situation. The structural analysis of the model mainly refers to the theory of "Hall three-dimensional structural model" in the system engineering theory, analyzes the lifelong inclusive education from all directions and multiple perspectives, and strives to build a space-time system that integrates everyone, all the time and everywhere.

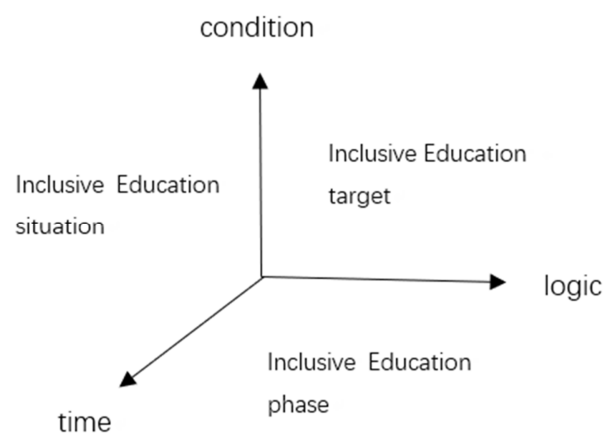

Figure 1. The 3D construction of lifelong inclusive education model. 
According to the theory of "Hall's three-dimensional structure model", the life-long inclusive education model is a three-dimensional spatial structure, which consists of three elements, namely, the inclusive education objects, the inclusive education stage and the inclusive education situation. Time dimension corresponds to the stage of lifelong inclusive education, including pre-school, school-age and post-school three stages. Logical dimension is the logic to solve the problem in every stage of time dimension. For example, in the model of lifelong inclusive education, taking the school-age stage as an example, the primary problem is to clarify the scope of inclusive education objects, which is the primary problem of constructing the system of life-long inclusive education. Therefore, in this study, logical dimension is locked into the scope of inclusive education object. Condition dimension corresponds to the situational factors of lifelong inclusive education, and it is a continuous space environment for realizing inclusive education, such as school, community and society.

According to the system engineering theory, the lifelong inclusive education model is holistic, relevant and ordered. It also shows that the lifelong inclusive education is a dynamic process of development, a process of continuous extension and development, and a process of continuous improvement on the basis of practice.

\subsubsection{Objects of Inclusive Education}

The objects of inclusive education are the core element of the model of lifelong inclusive education, which is the first problem to be solved in the process of model construction. The inclusive education objects in this model refers to the students with special education needs in a broad sense, including the students with visual impairment, hearing impairment, intellectual disability, limb disability, cerebral palsy, autism spectrum disorder, multiple disorders, learning disabilities (attention deficit hyperactivity disorder, reading disorder, writing disorder, mathematics learning difficulties, etc.), emotional behavior disorders, speech language disorders, abnormal and sick students, etc. Specifically, the inclusive education objects in the lifelong inclusive education model include disabled students, handicapped students and gifted students.

\subsubsection{Stages of Inclusive Education}

The Stages of inclusive education is an important element of Lifelong Inclusive Education Model. Special Education Enhancement Plan II (2017-2020) clearly proposed that inclusive education should be extended from compulsory education to pre-school and post-school stages. The top-level design should be viewed from the perspective of life-long education system, and build a lifelong inclusive education system that spans the whole process of individual life and all stages of career education development. In view of the current development stage of inclusive education in China, which is mainly in the school-age stage, and constantly expanding to the pre-school and post-school stages, the Lifelong Inclusive Education Model is divided into three stages, namely, pre-school, school-age stage and school-age. The construction of life-long inclusive education system should pay attention to the pre-school stage, so that each education object can receive loose and inclusive education from the early stage of life to the whole career development stage.

\subsubsection{Situations of Inclusive Education}

The situations of lifelong inclusive education are based on various situations such as school, community and society, forming the space environment of lifelong inclusive education.

In the context of school, lifelong inclusive education refers to the narrow sense of inclusive education, which means that on the premise of equality and non-discrimination, children with special education needs should be arranged in the general education environment of their community as much as possible, such as kindergarten, general primary and secondary schools, higher education institutions and other regular education institutions to study, and provide the support and help most suitable for their needs, which is the non-learning style Children with special education needs of different abilities and backgrounds can get the best public education services possible.

In the community context, lifelong inclusive education points to community integration. Community is an important field for the implementation of inclusive education [17]. The implementation of inclusive education in community can be a close combination of school education and community education, changing the state of school education, family education and community education being independent and isolated from each other. Social integration is an ultimate goal of lifelong inclusive education. Social integration refers to the interaction process between individuals or groups and social environment for the purpose of harmony [18]. At the level of social integration, inclusive education includes three meanings: first, social integration; second, cultural integration; third, psychological integration. With the proposal of "lifelong education", education not only covers all stages of a person's career development, but also includes all aspects of a person's life. Therefore, lifelong inclusive education should point to social integration.

\subsection{Hierarchical Structure}

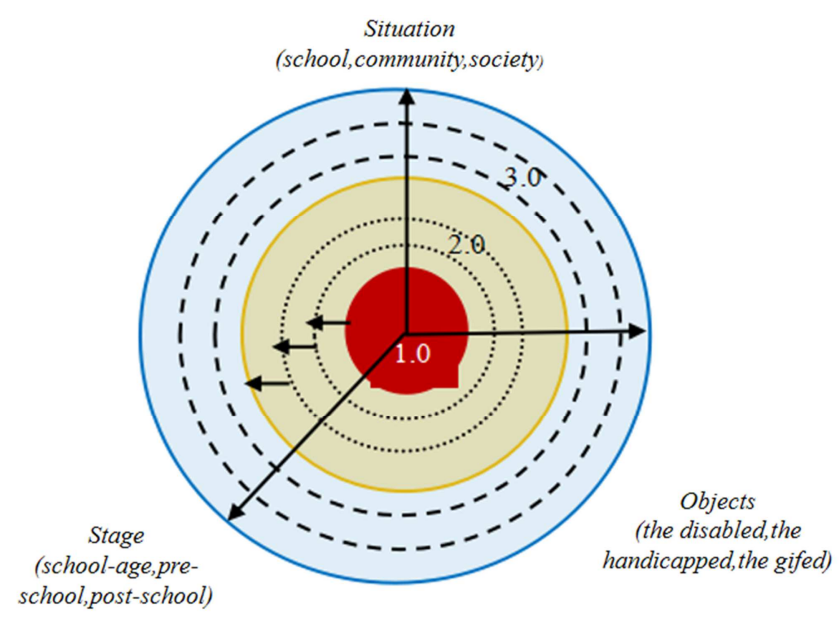

Figure 2. The Overlap Development of Inclusive Education. 
Lifelong inclusive education model is a three-dimensional structure including one core and six circles. The three elements in the model are characterized by "dynamic integration", which extends outward continuously and realizes the integrated development.

\subsubsection{The First Level of Lifelong Inclusive Education}

The first level of life-long inclusive education model points to the traditional mainstreaming, that is, the inclusive education objects focus on the disabled students, the inclusive education stages mainly focus on the compulsory education stage, and the inclusive education situation focuses on the school scope. From the perspective of inclusive education objects, the subjects of mainstreaming in China mainly refer to visual disability, hearing disability and intellectual disability, and some developed areas have expanded to 6-9 categories [19], including physical disability and mental disability, in addition to visual disability, hearing disability and intellectual disability.

It can be seen that the first level refers to the inclusive education for the students learning in regular class in the compulsory education stage (school-age stage) in the context of the school. At present, the inclusive education in most regions of Chinese mainland is at this stage.

\subsubsection{The Second Level of Lifelong Inclusive Education}

The second level of Lifelong inclusive education Model expands outward on the basis of the first level, changes in the core elements, little changes in the space-time elements, or stays at the concept level, yet not highlighted in the educational practice.

For example, the objects of inclusive education have expanded, no longer limited to narrow disabled students, and some disabled students have gradually attracted attention, such as LD, ADHD, EBD, and some regions have paid attention to gifted students (GS). At the same time, in view of the above handicapped students and gifted students, we have made active exploration and attempt in the top-level design, education and teaching, curriculum construction, family support and other aspects.

It can be seen that the second level of lifelong inclusive education has achieved a breakthrough in the objects of inclusive education, but there is little change in the other two elements. Although attention has been paid to handicapped students and gifted students, inclusive education in compulsory education is still the main stage. Most regions have not paid attention to the inclusive education in the pre-school and post-school stages, or the inclusive education in the community and social situation, or a small number of regions have advanced ideas and have not formed practical experience. At present, inclusive education in the developed areas of Chinese mainland, such as Beijing, Shanghai, Guangzhou, Jiangsu and Zhejiang, are at this stage.

\subsubsection{The Third Level of Lifelong Inclusive Education}

The third level of lifelong inclusive education model continues to extend outward on the basis of the first and second levels, breaking through the scope of inclusive education objects, and also breaking through the two elements of inclusive education stages and inclusive education situations. That is to say, it has realized the extension of age, not only focusing on the compulsory education stage, but also gradually extending the service age to the pre-school and post-school, and the education situation is not limited to the school, but to the community and social organizations, gradually realizing the construction of the lifelong inclusive education system.

For example, on the basis of the regional lifelong special education system [20], Changning District of Shanghai has realized the construction of the lifelong inclusive education service system. Based on the support system of Learning In Regular Class and practice promotion strategy, Changning District focuses on the inclusive education in the compulsory education stage, extends to both pre-school and post-school, develops the inclusive education transition service in each school stage, constructs the lifelong service mechanism for special education demanders from preschool inclusive education to higher inclusive education, and realizes the "horizontal to side, vertical to bottom" public service of regional special education, We have explored and formed a regional inclusive education service system with Chinese characteristics, covering the services of three types of special education objects: the disabled, the handicapped and the gifted.

\section{An Empirical Analysis of Lifelong Inclusive Education}

The Model is mainly demonstrated from two aspects, which are literature database and practical cases, as the basis of Lifelong inclusive education Model.

\subsection{The Analysis of Litezrature}

In Cnki Net of China, with "learning in regular class" as the key word, select "SCI source journal", "core journal" and "CSSCI" as the source category, and retrieve 313 articles in total, with the retrieval date of December 6, 2019. It is found that from 1992 to 2018, the number of publications with the key word of "learning in regular class" continued to rise. At the same time, the top ten subjects (except for countries) are learning in regular class, disabled children, special children, special education, blind, dumb and deaf education, integrated education, inclusive education, general schools, the students learning in regular class and disabled students (see Figure 2). The next ten are resource classrooms, special education schools, special schools, special education teachers, compulsory education, general children, autistic children, general primary school students, students with mild intellectual disability and disabled education.

In the same way, the key words of "inclusive education" were used to search for 238 documents. The number of documents continued to rise and the increase was large. At the same time, the top ten related topics (excluding irrelevant topic words) were inclusive education, special education, 
mainstreaming, blind, dumb and deaf education, disabled children, disabled students, special education teachers, general education, migrant workers children. It is noteworthy that kindergarten, general school and preschool inclusive education have entered the top 20 .

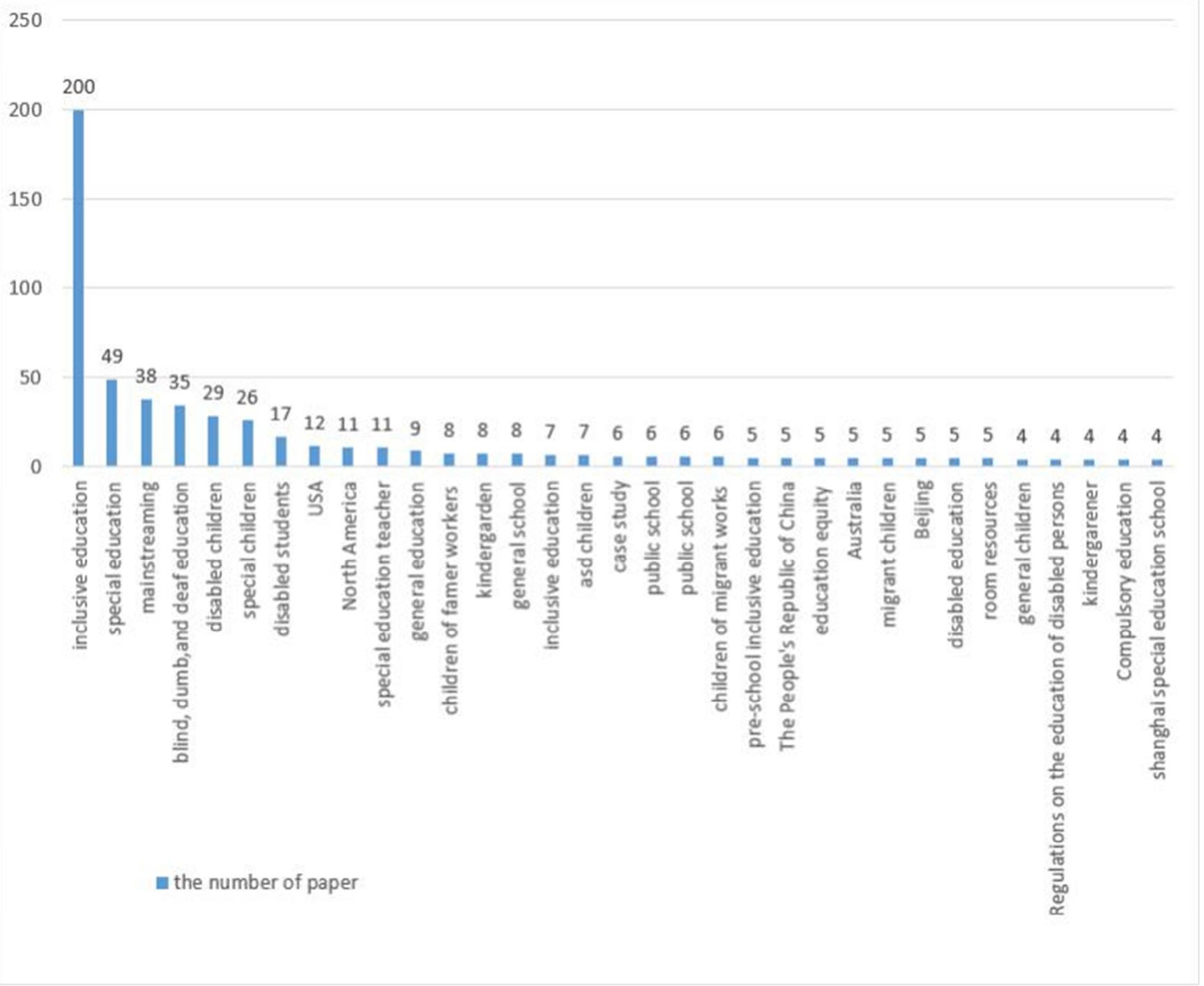

Figure 3. Theme analysis with inclusive education as key words.

Table 1. Ranking table of related subject words searched with key words of regular class study or inclusive education.

\begin{tabular}{|c|c|c|}
\hline Key words & Top Ten Topic Words & After Ten Topic Words \\
\hline $\begin{array}{l}\text { learning in } \\
\text { regular class }\end{array}$ & $\begin{array}{l}\text { mainstreaming, disabled children, special children, special } \\
\text { education, blind, dumb and deaf education inclusive education, } \\
\text { integrated education, general school, inclusive school students, } \\
\text { disabled students }\end{array}$ & $\begin{array}{l}\text { Room resources, special education school, special school, special } \\
\text { education teacher, compulsory education, general children, autism } \\
\text { spectrum disorder, general primary students, low-grade } \\
\text { intellectual-disability students, education of disabled person }\end{array}$ \\
\hline $\begin{array}{l}\text { integrated } \\
\text { education }\end{array}$ & $\begin{array}{l}\text { integrated education, special education, mainstreaming, blind, } \\
\text { dumb and deaf education, disabled children disabled students, } \\
\text { special education teacher, general education, children of migrant } \\
\text { workers }\end{array}$ & $\begin{array}{l}\text { nursery school, general school, inclusive education, autism } \\
\text { spectrum disorder children, case study public schools, public } \\
\text { schools, migrant workers moving with them, preschool inclusive } \\
\text { education, education equity }\end{array}$ \\
\hline $\begin{array}{l}\text { inclusive } \\
\text { education }\end{array}$ & $\begin{array}{l}\text { inclusive education, inclusive education, blind, dumb and deaf } \\
\text { education, mainstreaming, disabled children special children, } \\
\text { general education, disabled students, general school, education } \\
\text { equity }\end{array}$ & $\begin{array}{l}\text { Idea of inclusive education, special education teacher, idea of } \\
\text { education, disabled person education, special education school, } \\
\text { room resources, basic idea, students of special education need, } \\
\text { children of migrant workers, classroom teaching }\end{array}$ \\
\hline
\end{tabular}

It is not difficult to find out from table 1 that at present in China, whether it is mainstreaming or inclusive education, it is closely related to disabled children or the education for the disabled. For example, blind and deaf education, disabled children, special children and other theme words are basically in the top five, and more attention is paid to compulsory education, such as general schools, general education, public schools and public schools When education is the key word 
for retrieval, kindergarten, preschool inclusive education and migrant workers' children have been concerned.

From the above analysis, we can see that, at present, the research and practice of Inclusive Education in China is still focused on inclusive education in schools for disabled children, that is, integrated education in regular classes.

\subsection{The Practicing Cases}

In the process of promoting lifelong inclusive education, based on the development of regional integration education, some parts of Chinese mainland have made some preliminary attempts and explorations in practice. This study selects classic cases to further elaborate the practical evidence of lifelong integrated education model. Although these cases can not represent the whole picture of the practice of lifelong integrated education, they show the dynamic and trend of the development of lifelong integrated education from one side, and jointly describe the development blueprint of inclusive, universal and lifelong lifelong integrated education.

On the basis of regional lifelong special education, the special education guidance center of Changning District of Shanghai is an entity special education guidance center, based on the local national culture and learning from the experience of foreign inclusive education reform, Focusing on the education goals of the 2030 agenda for sustainable development of the UN Development Summit, the Institute of lifelong integrated education has been established, and bold exploration has been made in the integration of education objects, education stages and education situations, from the macro, meso and micro aspects. The construction of life-long inclusive education service system provides Chinese samples for the practice of inclusive education, which has a breakthrough significance for promoting the development of inclusive education in China.

In the scope of inclusive education services, it has expanded from the traditional three types of disabled students to three categories of disabled students, including disabled, handicapped and gifted students, and innovated the practice mode. Taking the project as the starting point, it has carried out four-dimensional service and support projects for integrated education schools, teachers, students and parents. For example, Aiming at the disabled students who have not been identified to study in regular classes, we have developed the "multi-disciplinary scientific research accreditation project", which invites multi-disciplinary experts to provide consultation and guidance, and also provides direct special education services for those who have not been identified as studying in regular classes (such as inviting Taiwan therapists to provide short-term speech therapy training for students with speech language disorders). For example, for the main objects of inclusive education (the handicapped students), we have developed the "Teacher centered group project" [21] to improve the special education literacy and intervention skills of regional inclusive education teachers. in 2013, we established the "Teacher centered group of emotional and behavioral barrier students' education", and then established the "ADHD student teacher centered group", "writing barrier centered group" and "positive behavior Support teachers' central group", etc. Another example is to carry out special training for families of students with special education needs (such as inviting international senior occupational therapists to carry out workshops for parents with dysgraphia). It supports the gifted students in the general school, introduces and revises the assessment tool guidance manual for gifted students' leadership skills screening test (regional version), establishes the regional norm, and develops the thinking training course project for the regional super normal students in 2014[22]. It can be seen that in the process of promoting inclusive education, Changning District of Shanghai has broken through the range of traditional learning objects of mainstreaming, served students in special education needs in a broad sense, including disabled, handicapped and gifted students, and made Chinese mainstreaming really move towards inclusive education.

In the inclusive education service stages, the education period have been extended, covering three stages: pre-school, school-age and post-school, and the title transition mechanism of each school section has been established to promote the regional lifelong inclusive education service. On the basis of school inclusive services for school-age disabled, handicapped and gifted students, we provide support and services based on their needs for the disabled and handicapped students in the pre-school stage and the disabled in the post-school stage. For example, 37 rank transition services have been developed and implemented in the five stages of homestead, kindergarten, junior high school, junior high school to primary school and post primary school [23]. Facing the preschool stage, we carried out "early intervention project", "preschool medical education and health care teacher center group", "early reading teacher center group", and so on. For another example, learning projects and mechanisms are constructed for adults in the post-school stage. For example, for the autistic group, we have developed the "employment support project for adults with autism spectrum disorder (ASD)". In order to support the people with mental disabilities to obtain higher education opportunities through the adult college entrance examination, in 2012, we promoted the cooperation between community colleges and special vocational schools, developed the "review class project for college entrance examination for students with mental disabilities", and implemented higher inclusive education through independent class arrangement and mainstreaming. At the same time, the "disabled elderly leisure and health care service project" has been developed for the deaf and mute elderly in the region. The above projects provide regional support for the lifelong learning and quality of life of students in regular classes.

At the same time of expanding the target of inclusive education and extending the stage of inclusive education, by integrating resources and taking community integration as the direction, we should actively develop lifelong inclusive education service projects and actively build a broader inclusive education ecosystem. For example, relying on the key project of the Ministry of education "deepening research 
on the construction of new special education schools responding to inclusive education (DHA160368)", the Ministry of education promotes the construction of new special education schools, advocates to actively respond to the development needs of inclusive education, breaks the traditional closed operation mode, carries out transformation, and becomes an inclusive education institution. Relying on this project, 48 sub project experimental schools in 15 provinces and cities have been formed nationwide, and five national academic seminars have been held to promote the experience of inclusive education to the whole country. For another example, taking picture books as the starting point, this paper puts forward "Inclusive Culture Picture Books", proposes four levels of inclusive culture (difference and diversity, understanding and acceptance, respect and equality, appreciation and win-win), and selects five 100 Inclusive Culture Picture Books to promote to regional primary and secondary schools (including kindergartens), such as the establishment of "central group of early reading teachers" and "Inclusive Culture Picture Books". This reading and teaching center group aims to promote the concepts of inclusive education to teachers and students in each section. Moreover, relying on the streets of communities, we have developed a community inclusive Picture Book Parent-child Reading Project, which will promote Inclusive Culture Picture Books to the community, promote the concepts of Iinclusive education to the Young Children and community residents. At the same time, we will promote the Inclusive Culture Picture Books by Fryer Picture Library and the WeChat official account of "Changning Special Education", so as to promote the concepts of inclusive education into the community and into the society, so that we can be equal, harmonious and friendly. The concepts of goodness and beauty permeates everyone's heart and promotes social integration.

\section{The Future of Inclusive Education in China}

According to the "Education 2030 programe of action " put forward to "ensure inclusive and fair quality education, promote lifelong learning opportunities for all" and the current situation of China's integrated education practice, the future development of inclusive education and international dialogue will achieve the following breakthroughs in china.

\subsection{Inclusive Education in China Is Moving from Mainstreaming to Inclusive Education}

International inclusive education is aimed at "students with special education needs", which includes both disabled students and learning disabled students. There are 13 types of special children in American special education service. In china, the inclusive education is mainly in the form of learning in regular classes. At first, special education services were mainly provided for children with three types of disabilities. With the promotion of learning in regular classes, "the types of special children receiving inclusive education continue to expand"[24], some developed regions in China havebeen expanded to 6-9 categories. It can be seen that the service coverage of regular class learning in China is further expanding, and it is believed that it will eventually move towards integrated education and even inclusive education.

\subsection{China's Inclusive Education Can Talk on the Same Platform Internationally}

Through the international comparison of inclusive education, it is found that the subjects of international inclusive education are mainly mild, such as six kinds of children with mild physical and mental disorders such as speech disorder, physical disability and illness in Japan. Although there are three main types of education vigorously implemented in mainland China: blindness, deafness and mental retardation [25], some developed regions have paid attention to the inclusive education of students with disabilities, such as Haidian District in Beijing and Changning District in Shanghai. Therefore, by expanding the target of inclusive education, let our regular classes go to inclusive education. On this basis, inclusive education in China can communicate and dialogue with regions with better development of international inclusive education, and make China's voice in the field of international inclusive education.

\subsection{China's Inclusive Education Can Take the Lead in Realizing Lifelong Inclusive Education}

the Education 2030 Framework for Action proposes to promote the opportunity of lifelong learning for all people, and inclusive education is bound to move towards lifelong inclusive education. In mainland China, relevant special education policies have been issued to promote the extension of special education to compulsory education; at the same time, special education institutions in some regions spontaneously cooperate with disabled persons' federation and community education institutions to pay attention to the community education services for special students after the compulsory education stage. Therefore, China's inclusive education has the innate advantage of moving towards lifelong inclusive education. It will promote the education period of the inclusive education object to preschool or birth, to adult education after vocational education, and even to education for the elderly, so as to build a life-long inclusive education service system from birth to the elderly. Although this process still needs some time, but we can implement it in stages, let's work together!

\section{Acknowledgements}

This is the phased research result of the key project of Ministry of Education of the People's Republic of China for the 13th Five-Year Plan of National Education Science in 2016 Deepening Research on the Construction of New Special Education Schools in Respond to Inclusive Education. (subject approval Number: DHA160368). Project leader is Feng Xia. We thank Yuzhen Xu, Meixian Huang, Lijiang, 
Yuyun Wen, Yongfen Gu, Xichun Yan, Zhen Tang, Shen'e Huang, Yao Wang, Shuqiong Yan, Aihua Dai, Caihong Hu, Yi Chen, Yan Wang for their efforts in this study.

\section{References}

[1] Candy, P. C. (1991). Self-Direction for Lifelong Learning: A Comprehensive Guide to Theory and Practice. San Francisco: Jossey-Bass.

[2] Cao, J. Q., \& Zan, F. (2003). A Comparative Observation of inclusive education in the United States, Japan and Mainland China. Chinese Journal of Special Education (Bimonthly), 04: 70-74.

[3] Cheng, T. S. (2011). Study on the sustainable development of Vocational Education in China under the theory of educational ecology. ZhIJIAO LUNYU, 01: 72-72.

[4] Deng, M., \& Su, H. (2012). Grafting and Re-generation of inclusive education in China: A Socio-cultural Analysis. Journal of Educational Studies, 01: 85-91.

[5] Deng, M., \& Zhu, Z. Y. (2007). "Learning in Regular Class" and inclusive education: A Comparison between Chinese and Western Model for Special Education. Journal of Huazhong Normal University (Humanities and Social Sciences), 04: 130-134.

[6] Du, L., \& Feng, Q. H. (2019). A Review of the Progress of International inclusive education Research and Its Enlightenment to China. Disability Research, 01: 21-26.

[7] Huang, Z. X., \& Wan, R. G. (2008). Community: an important field for the implementation of inclusive education. Research on Education Development, 23: 85-87.

[8] Li, J. L. (2009). The Unique Advantage of Situational Education and Its Construction. EDUCATIONAL RESEARCH, 03: 52-59.

[9] Li, Y. X. (2004). The Idea and Implementation Policy of Lifelong Education in China. Peking University Education Review, 2, 58-62.
[10] Luo, F. (2000). The Analysis of Definition Development of Special Education for Thirty Years. Chinese Journal of Special Education, 25 (1): 5-7.

[11] Pu, J., \& Zhang, L., \& Xie, S. B. (2012). Review of the Experimental Study of the Situation Education in China. Education and Learning Research, 06: 103-106.

[12] Tian, X. P. (2016). Community Construction of Innovation and Entrepreneurship Education from the Perspective of Educational Ecology Theory. Research on Education Development, 07: 66-72.

[13] Xi, F., \& Xu, Y. Z. (2016). On the Service System for Regional Lifelong Special Education Based on Lifelong Learning for All-Practice from Changning District, Shanghai. Chinese Journal of Special Education, 10.

[14] Xia, F. (2016). The construction of regional lifelong special education service system - Practice from Changning District. A Journal of Modern Special Education, 11, 19-22.

[15] Xia, F., \& Xu, Y. Z. (2014). Pay attention to the career development of disabled students - research and Practice on the service of changing the rank of disabled students in Changning District, Shanghai. A Journal of Modern Special Education, 12: 4-7.

[16] Yan, S. Q. (2016). The construction of teacher's special subject center group in the perspective of integrated education. A Journal of Modern Special Education, 03: 18-20.

[17] Yang, Z. W. (2019). Educational Goals in 2030 Agenda for Sustainable Development and Chinese Action Strategy. Global Education, 6.

[18] Zhang, H. L. (2010). The Comment and the Application of Super's Career Development Theory. Journal of Yunnan University of Finance and Economics, 04: 156-162.

[19] Zhang, Z., \& Yu, Z. F., \& Fang, J. M. (2013). Enlightenment and Comparison between Chinese and American inclusive education. Comparative Education Review, 11: 100-104. 